\title{
Effects of the Pressure and Finishing Agents on the Water Absorption of Cotton Fabric
}

\section{Saiji Higuchi ${ }^{* 1}$, Atsushi Suzuki ${ }^{* 2}$, Minoru Kubota ${ }^{* 3}$, Yuichi Masubuchi ${ }^{* 4}$, Jun-ichi Takimoto*4, and Kiyohito Koyama ${ }^{* 4}$}

\footnotetext{
${ }^{* 1}$ Nagasaki Prefectural Women's Junior College 1-4-1 Narutaki, Nagasaki-city, Nagasaki, 850 Japan

${ }^{* 2}$ Faculty of Education, Nagasaki University 1-14 Bunkyo, Nagasaki-city, Nagasaki, 852 Japan

${ }^{* 3}$ Fukuoka Industrial Technology Center 332-1 Kamikoga, Chikushino-city, Fukuoka, 818 Japan

${ }^{* 4}$ Faculty of Engineering, Yamagata University 4-3-16 Jonan, Yonezawa-city, Yamagata, 992 Japan
}

\begin{abstract}
The relation between the pressure-dependence of water absorption and the compression characteristics of cotton fabrics, and the changes in the water absorption of the fabrics by the treatment of a softener, thickener, or a mixture of them were investigated. The initial water absorption rate of the cotton fabric increased with the pressure, and was equilibrated at $626 \mathrm{~Pa}$ or above. The compression ratio also increased with the pressure, reached about $25 \%$ at the pressure of $626 \mathrm{~Pa}$, where the initial water absorption rate was eqilibrated, and continued to increase after this point. The time needed for the saturation of water was shortened with the increase in the pressure, showing the peaks of the saturation of water at the pressure of $210 \mathrm{~Pa}$ and $349 \mathrm{~Pa}$. No changes were observed in the compression-characteristics of the fabrics with the treatment of the finishing agents (softener, thickener or the mixture of them) or with the treating times. However, the amount of absorbed water at $626 \mathrm{~Pa}$ showed the most decrease in the fabric treated with a softening agent of the all finishing agents examined. The amount of absorbed water was increased in the fabric treated with a thickening agent compared with the untreated fabric when the treating time was 2 minutes or longer. Changes in the amount of absorbed water with the treating time was smallest in the fabric treated with a mixture of the softener and the thickener.
\end{abstract}

\section{Introduction}

The water absorption of textiles such as cloths and towel is an important aspect of their hygienic quality. The level of comfort when using a towel is mostly determined by the rate with which it absorbs water immediately after the towel touches the skin[1]. The initial water-absorbing rate of fabric, together with the saturation amount of absorbed water, is an important factor to evaluate the characteristics of the water absorption. Thus, we think to measure the initial water absorption rate because it is an important factor to evaluate the water absorption. For the measurement of the water absorption, there is the Larose method which allows measurements of the rate and amount of absorbed water adjusted for the force of compression in a manner simulative of actual wearing or use of textiles. In the measurement of the water absorption of fabric by this Larose method, there are problems such as the inadequate accuracy due to the excessive rate of absorbed water. The amount of absorbed water of cotton fabric used in this study was saturated in 2 5 seconds by this Larose method. Because the water absorption rate of cotton fabic was large, the change 
with the passage of time of the amount of absorbed water was not measured and the initial water absorption rate of cotton fabric was not calculated. There is modified Larose method which easily measure the initial amount of absorbed water because of inserting a polyester sheet between the glass filter and the sample fabric [2]. With reference to the modified Larose method, in this study, we thought out the method which was measured the initial water absorption rate and the saturation amount of absorbed water about even thin sample fabric. We used a water absorption meter based on the Larose method inserting a polyester-doughnut-sheet between the glass filter and the sample fabric and applying polyester sheet as the weight on the acrylic plate to be placed on the sample fabric that came be in contact with the weight. This method was devised to hold a fabric between the polyester sheets. By this method, the initial water absorption rate of even thin cotton broadcloth was calculated by the measurment of the amount of absorbed water.

It is known that the initial water-absorbing rate of pile fabrics increases as the compressive pressure becomes higher, and that the time required until the amount of absorbed water reaches a saturated level tends to decrease as the compressive pressure becomes higher (3). In the assessment of the water absorption, the water absorption rate of fabric is an important factor to evaluate the characteristic of the water absorption. The pressure to the fabric is an important factor that determines the initial water absorption rate and the saturation amount of absorbed water. By the method thought out with us, it was able to evaluate the relationship between the water absorption of cotton broadcloth measured by this method at different pressure levels and its compression characteristics examined a compression tester.

Also, by this method, we measured the amounts of absorbed water of the cotton fabric treated with a softening agent, thickenig agent, and the mixture of them to study the effects of various treatments on the water absorption. Such a study of the water absorption is considered to be necessary, particulaly because data concernig the water absorption treated with a softening agent are extremly scarce in the field of the science for textile end-uses[4].

\section{Experiment}

\subsection{Sample}

Table 1 shows the characteristics of cotton sample fabric. Its texture was the basic plain weave. This cotton broadcloth was used after washing with carbon tetrachloride, rinsing with water, and drying according to the simple pretreatment procedure described in JIS L 1030.

Table 1 Detailes of Cotton Fabric

\begin{tabular}{|c|c|c|c|c|c|c|}
\hline \multirow[t]{2}{*}{ Fabric } & Textile & Weight & Thickness & $\begin{array}{l}\text { Dens } \\
\text { (thread }\end{array}$ & $\begin{array}{l}\text { sity } \\
d /(\mathrm{cm})\end{array}$ & $\begin{array}{l}\text { Count } \\
\text { (tex) }\end{array}$ \\
\hline & Weave & $\left(\mathrm{g} / \mathrm{m}^{2}\right)$ & $(\mathrm{mm})$ & Warp & Weft & Warp Weft \\
\hline Broadcloth & Plain & 114.7 & 0.24 & $j_{2}$ & 26 & $14.4 \quad 15.0$ \\
\hline
\end{tabular}

\subsection{Compression characteristics}

Compression characteristics of the cotton fabric were examined using the compression tester KES.FB3. Conditions of measurement were: compression area 2 $\mathrm{cm}^{2}$, compressional deformation rate $20 \mu \mathrm{m} / \mathrm{sec}$, and maximum compression pressure $50 \mathrm{~g} / \mathrm{cm}^{2}$. The measurement was performed in a climatic room adjusted to a temperature of $20{ }^{\circ} \mathrm{C}$ and a relative humidity of $65 \%$.

\subsection{Treatment with finishing agents}

The sample fabric were treated with a softening agent for the domestic use whose primary component was dioleyldimethylammonium chloride and whose effects on the water absorption has recently been improved [5], a thickening agent was a preperation for domestic use consisting primarily of polyvinylacetate with improved adsorbing properties and solubility(6). or both. The concentrations of the softening agent and thickening agent were $0.22 \mathrm{ml} / 1$ and $8 \mathrm{ml} / 1$, respectively. Also, the treating time was changed to 8 levels from 30 seconds to 40 minutes, and the bath ratio was adjusted to 1:300. The solution temperature during the treatment was $20-24{ }^{\circ} \mathrm{C}$. The treated fabric was air-dried and ironed before measurement.

\subsection{Evaluation of the water absorption}

The absorption was evaluated by measuring the amount of water absorbed by the fabric using a water absorption meter based on the Larose method (TL.01, Toyobo Engineering). In this study, the amount of absorbed water was measured with the sandwich of the 
cotton fabric between polyester sheets (Fig.1). The size of the doughnut sheet was $0.1 \mathrm{~mm}$ thick, $63 \mathrm{~mm}$ in external diameter, and $20 \mathrm{~mm}$ in internal diameter. The cotton fabric $60 \mathrm{~mm}$ in diameter was put on the doughnut sheet, and an acrylic resin plate to which a polyester sheet was pasted and the weight were placed on the resin plate. The pressure applied to the fabric was adjusted by changing the weight. The difference in height between the graduated pipette for measurement of the amount of absorbed water and the surface of the glass filter was set at $30 \mathrm{~mm}$. The temperature of the distilled water used for the measurement was kept between $22^{\circ} \mathrm{C}$ and $26^{\circ} \mathrm{C}$. The amount of absorbed water was expressed as a mean of 5 sample fabrics. The initial water absorption rate was calculated from the amount of water absorbed during 30 seconds from the beginning of water absorption. Water absorption was considered to have been saturated when more than 5 minutes was needed for absorption of $0.01 \mathrm{ml}$ or more water. The temperature and relative humidity of the laboratory were $22 \sim 26{ }^{\circ} \mathrm{C}$ and $62 \sim 73 \%$, respectively.

\section{Results and Discussion}

3.1 Pressure dependence on the amount of absorbed water and on the compression characteristics of cotton fabric

Fig. 2 shows the relationship between the amount of water absorbed and the time for the water absorption

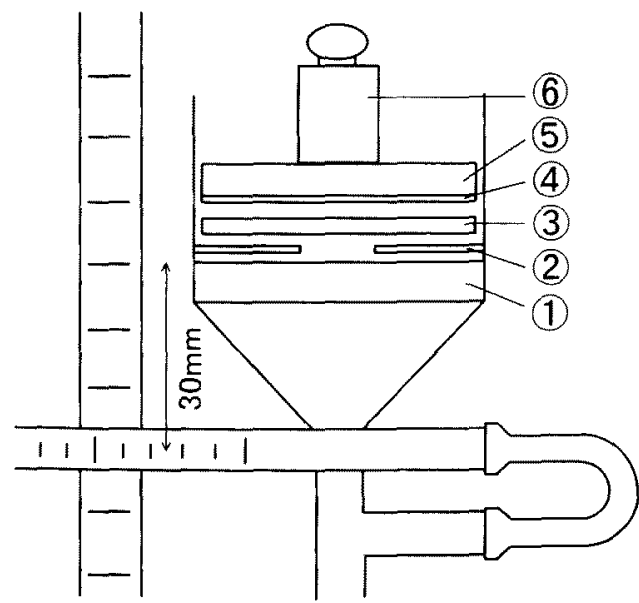

Fig. 1 Main part of measurement apparatus. (1)Glass Filter; (2)Polyester Doughnut Sheet; (3)Cotton Fabric; (4)Polyester Sheet; (5)Acrylic Resin Plate; (6)Weight by untreated cotton fabric. Fig. 3 shows the initial water absorption rate and the amount of water saturated. The initial water absorption rate increased with the increase of the pressure from $106 \mathrm{~Pa}$ to $210 \mathrm{~Pa}, 349 \mathrm{~Pa}$, and $626 \mathrm{~Pa}$, but it did not change further when the pressure was increased from $626 \mathrm{~Pa}$ to $904 \mathrm{~Pa}$ and 1805 $\mathrm{Pa}$. When the pressure was $106 \mathrm{~Pa}$, water absorption reached saturation at $0.47 \mathrm{ml}$ after 620 seconds, but when the pressure was $210 \mathrm{~Pa}$ and $349 \mathrm{~Pa}$, the amounts of saturated water were both $0.50 \mathrm{ml}$, and the times until the saturation were 298 seconds and 215 seconds, respectively. The initial water absorption rate increased, and the time for the saturation was shortened, with the increasing pressure, and the results were consistent with the report by Shiomi et al.(3). However, when the pressure was increased further to $626 \mathrm{~Pa}, 904 \mathrm{~Pa}$, and $1805 \mathrm{~Pa}$, saturation was observed at $0.49 \mathrm{ml}, 0.47 \mathrm{ml}$, and $0.45 \mathrm{ml}$ respectively at 140 seconds, 100 seconds, and 89 seconds after. The time until the saturation was shortened, but the saturation amount of absorbed water was decreased, and the initial water absorption rate remained constant when the pressure increased.

Fig. 4 shows the compression characteristics of the cotton fabric. The compression ratio $\alpha$ was calculated by equatio (1), in which To is the thickness of the fabric at a pressure of $0.5 \mathrm{~g} / \mathrm{cm}^{2}[7]$ and $\mathrm{T}$ is the thickness at a compression process $[8]$.

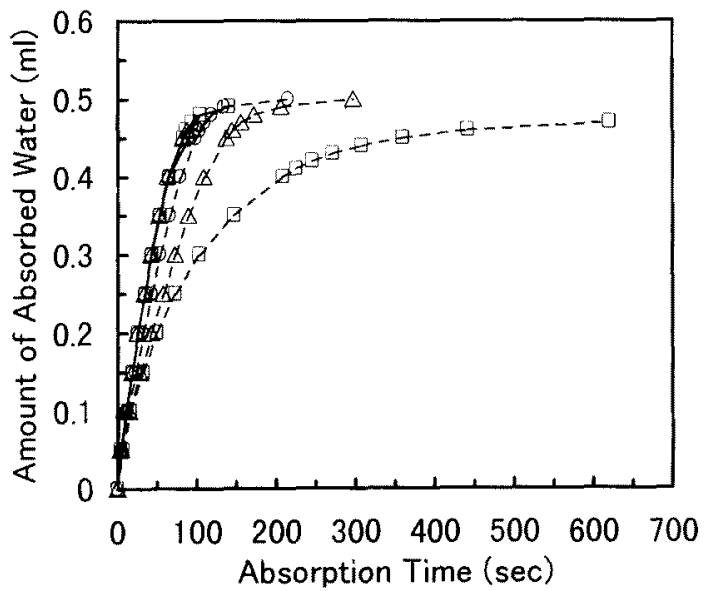

Fig. 2 Relationship between the amount of absorbed water and the absorption time of cotton fabric at $106 \mathrm{~Pa}(-\boxminus) ; 210 \mathrm{~Pa}(-\Delta) ; 349 \mathrm{~Pa}(-\odot)$; $626 \mathrm{~Pa}(\boxminus) ; 904 \mathrm{~Pa}(\Delta) ; 1805 \mathrm{~Pa}(-)$. 


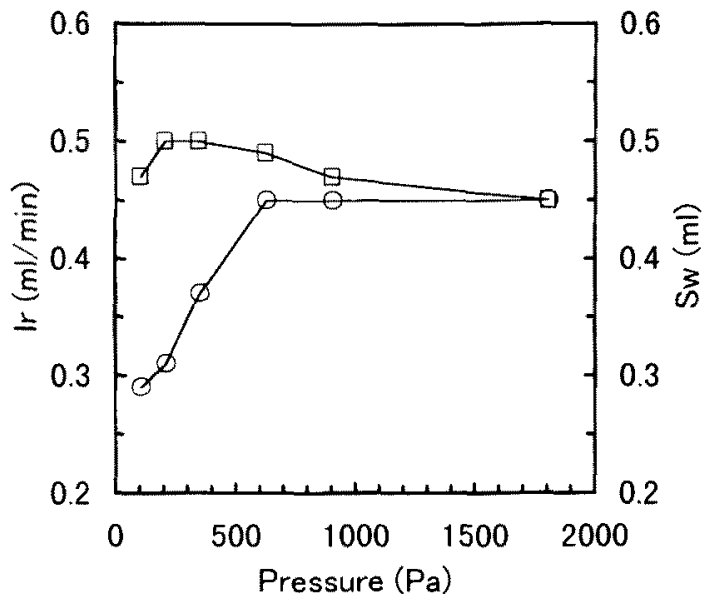

Fig. 3 Relationship between the initial water absorption rate $\operatorname{Ir}(O)$ or saturation amount of absorbed water $S w(\square)$ of cotton fabric and pressure.

$$
\alpha=\frac{\mathrm{T}_{0}-\mathrm{T}}{\mathrm{T}_{0}} \times 100
$$

The amount of absorbed water was measured at 6 pressure levels ranging from $106 \mathrm{~Pa}$ to $1805 \mathrm{~Pa}$. Fig.5 shows the relation between the compression ratios at various pressure levels and the pressure at the maximum compression pressure of $50 \mathrm{~g} / \mathrm{cm}^{2}$ from the data in Fig.4. The compression ratio increased markedly with early increases in the pressure and somewhat slowly with subsequent pressure increases. Fig. 3 and Fig. 5 indicate that the initial water absorption rate increased with the pressure but that it was fixed at $0.45 \mathrm{ml} / \mathrm{min}$ at $626 \mathrm{~Pa}$ or above despite of the progressive increases in the pressure. The

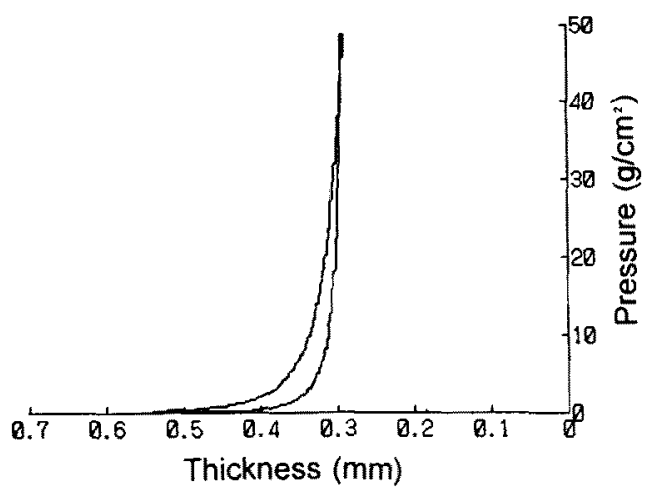

Fig. 4 Compression characteristics of cotton fabric. compression ratio when the initial water absorption rate was equilibrated was approximately $25 \%$.

These results may be explained by the changes in the contact area of the cotton fabric with the glass filter and the changes in the state of the void in the fabric with increase in the pressure applied to the fabric $(3,9)$. The contact area was reported to be increased with the pressure [3]. In this study, also, the contact area of the fabric with the glass filter was considered to be increased with the increase in the pressure from $106 \mathrm{~Pa}$ to $626 \mathrm{~Pa}$, facilitating the infiltration of water into the fabric and increasing the initial water absorption rate and the amount of absorbed water. However, the initial water absorption rate showed no further changes when the pressure was increased from $626 \mathrm{~Pa}$ to $904 \mathrm{~Pa}$, probably because the contact area of the fabric with the glass filter did not increase further with the additional increase in the pressure. Also, the amount of the

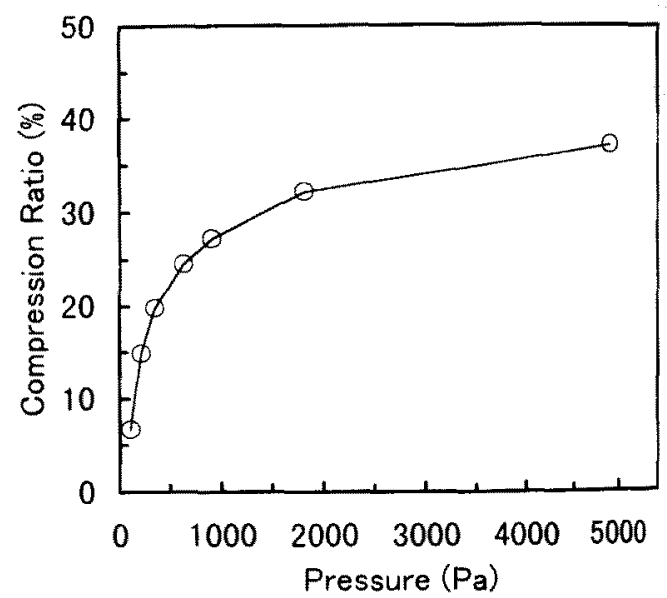

Fig. 5 Relationship between compression ratio of cotton fabric and pressure.

saturated water was maximum at $0.5 \mathrm{ml}$ when the pressure was $210 \mathrm{~Pa}$ and $349 \mathrm{~Pa}$, and it decreased to 0.45 $\mathrm{ml}$ with further increase in the pressure to $1805 \mathrm{~Pa}$. The voids in an aggregate of fibers are reported to decrease when they were compressed [9-12], and interruptions are considered to develop in the void when it decreases (13). In this study, also, these changes are considered to have prevented the infiltration of water into the fabric, causing a decrease in the saturation amount of absorbed water.

Compression characteristics were measured in the 
cotton fabrics treated with a softening agent, a thickening agent, and a mixture of them. Fig. 6 shows the changes in the compression ratios with the finishing time. The compression ratio was not dependent on the treating time or the finishing agents at a pressure of 626 $\mathrm{Pa}$ and became constant nearly at $25 \%$. No changes according to the treating time or the finishing agents were observed at other pressure levels. The linearity of compression characteristics, compression energy, and compression resilience also showed no changes with changes in the treating time or the finishing agents.

Fig. 2 indicates that the rate and amount of absorbed water were dependent on the pressure and that the initial water absorption rate became constant at pressures of $626 \mathrm{~Pa}$ and above, and Fig. 6 indicates that compression characteristics of the cotton fabric were not dependent on the finishing agents or the treating time. We, therefore, measured the amount of absorbed water of the cotton fabric treated with a softening agent, a thickening agent, or a mixture of them at a pressure of $626 \mathrm{~Pa}$ and evaluated the effects of the finishing agents and the treating time on the amount of absorbed water.

\subsection{Effect of the finishing agent on the amount} of absorbed water

Fig. 7 shows the relationship between the amount of absorbed water and the absorption time in the cotton fabrics treated with a softening agent, a thickening

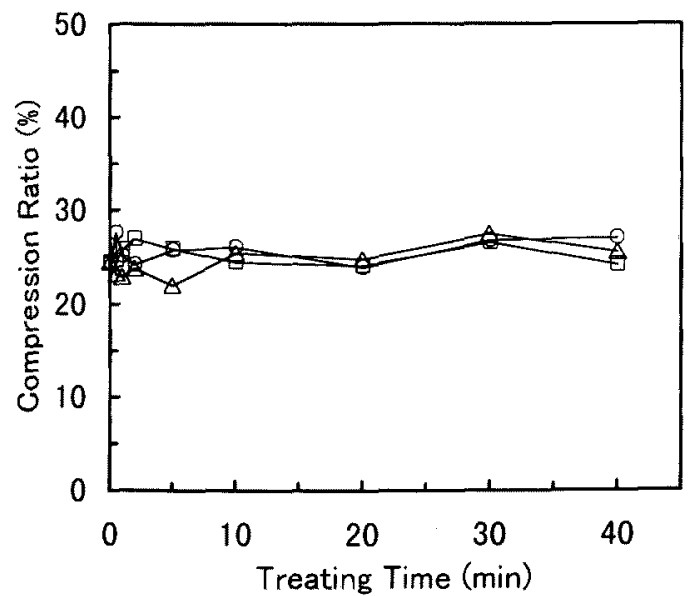

Fig. 6 Relationship between compression ratio and treating time of cotton fabric treated with softening agent $(O)$; thickening agent $(\Delta)$; the mixture of them $(\square)$. agent, and their mixture when the treating time was 5 minutes. The water absorption rate of the fabric treated with the softening agent was markedly decreased compared with nontreated fabric. In contrast to this, the water absorption rates of the fabrics treated with the thickening agent or the mixture of softening agent and thickening agent seem to agree with that of nontreated fabric. As the initial water absorption rate of fabric is an important factor to evaluate the characteristics of the water absorption, the relationship between the amount of absorbed water when the absorption time is 30 seconds and the treating time was investigated.

Fig. 8 shows the relationship between the amount of absorbed water and the treating time in the cotton fabrics treated with a softening agent, a thickening agent, and their mixture when the water absorption time was 30 seconds. The amount of absorbed water decreased in all treated fabrics when the treatment time was 30 seconds to 1 minute. That of the fabric treated with a softening agent decreased by $0.09 \mathrm{ml}$ from 0.22 $\mathrm{ml}$ to $0.13 \mathrm{ml}$ when the treatment time was 30 seconds, and this decrease was the greatest among the fabrics treated with various agents. When the water absorption of cotton fabric treated with a softening agent was measured by the Bilec method, the height of absorbed water was reported to have decreased with the

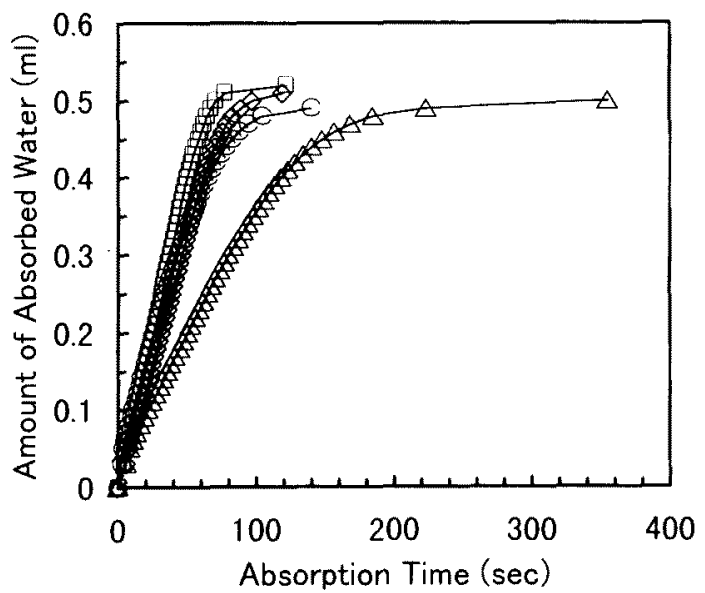

Fig. 7 Relationship between amount of absorbed water and absorption time of cotton fabric treated with nontreated $(O)$; softening agent $(\Delta)$; thickening agent $(\square)$; the mixture of them $(\diamond)$ when treating time is 5 minutes. 
increasing treating time, shown a minimum value when the treatment time was 10 minutes, but recovered slightly with prolonged treating times[14]. In this study, however, the amount of absorbed water decreased gradually with the increase of the treating time and showed no recovery. It is said that surfactants are adsorbed in a greater amount with prolongation of the treatment time[15], and since they are adsorbed with their hydrophilic groups directed to the surface of the fibers directing their hydrophobic groups to the opposite side, they are reported to make the surface of the fibers hydrophobic and to increase the contact angle between the fibers and water[16]. Therefore, the amount of absorbed water decreased with prolongation of the treating time, presumably because the hydrophobic groups of dioleyldimethylammonium chloride were directed to the surface of cotton fibers preventing infiltration of water into the cotton fabric.

The amount of absorbed water in the cotton fabric treated with a thickening agent decreased by $0.07 \mathrm{ml}$ from $0.22 \mathrm{ml}$ to $0.15 \mathrm{ml}$ when the treating time was 30 seconds, but the decrease was smaller than that in the cotton fabric treated with a softening agent. Since polyvinylacetate is insoluble in water, it decreases the rate and amount of absorbed water when it is adsorbed on the cotton fabric. However, as it is not water-repellent as is the hydrophobic groups of the

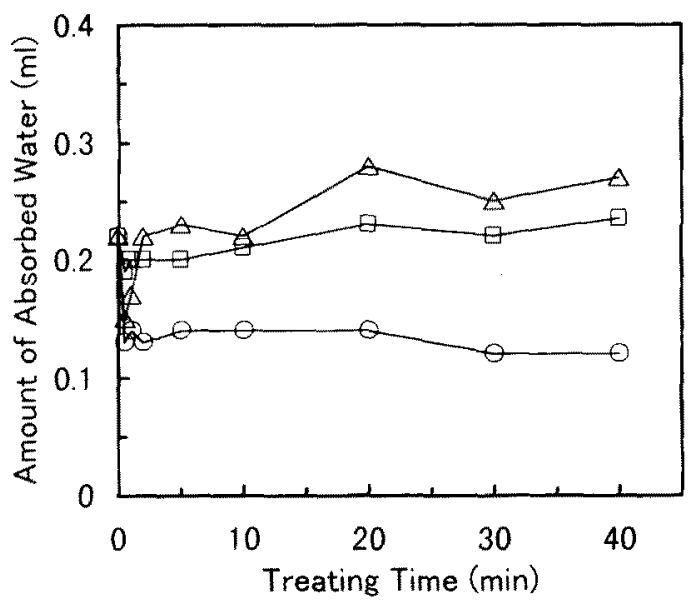

Fig. 8 Relationship between amount of absorbed water and treating time of cotton fabric treated with softening agent $(O)$; thickening agent $(\Delta)$; the mixture of them $(\square)$ when water absorption time is $30 \mathrm{sec}$. surfactants in softening agents, the decrease in the amount of absorbed water is considered to be smaller in the cotton fabric treated with the thickening agent than in the cotton fabric treated with the softening agent. The amount of absorbed water recovered when the treating time was 2 minutes or longer and became greater than that of the untreated cotton fabric. The amount of absorbed water is considered to have recovered, because the fine capillaries formed between the surfaces of polyvinylacetate coating on the cotton fibers facilitated the penetration of water. In our previous study [14], the height of absorbed water measured by the Bilec method was slightly lower than in the untreated cotton fabric and was the minimum when the treating time was 30 seconds to 1 minute, but it recovered with further prolongation of the treatment time. Similar results were obtained also in the present study.

The amount of absorbed water in the cotton fabric treated with the mixture of the softening agent and the thickening agent decreased by only $0.03 \mathrm{ml}$ from 0.22 $\mathrm{ml}$ to $0.19 \mathrm{ml}$ when the treating time was 30 seconds, and it tended to recover gradually when the treating time exceeded 1 minute. In the previous study \{14], the height of absorbed water measured by the Bilec method was smaller in the cotton fabric treated with the mixture than in the untreated cotton fabric and decreased slowly with the prolongation of the treatment time. However, in this study, the amount of absorbed water decreased temporarily and recovered gradually with prolongation of the treatment time and tended to increase.

\section{References}

1. Y. Yamaguchi and M. Nagayama, Sen-i Gakkat Preprints 1994 (G), p G.46 (1994).

2. J. Seta, S. Nakamura, and T. Nishimura, J. Home Econ. Japan, 48, 515(1997).

3. A. Shiomi, K. Abe, and N.Maeda, Sen'i Seinin Shoh! Kagaku, 31, 202 (1990).

4. K. Yoshizumi, K. Harada, Y. Kobayashi, M. Aita, M. Nagayama, and Y. Yamaguchi, Sen-i Gakkashi, 49, 448(1993).

5. K. Tsuji, Sen'i Seihin Shohi Kagaku, 36, 736(1995).

6. T. Fujii, 'Senzai - senjou no jiten」 (Edited by H. Okuyama and M. Minagawa), Asakura Shoten 
p. 458(1991).

7. S. Kawabata, Sen'i Kikai Gakkaishi, 26, 721 (1973).

8. R.Kinoshita, J. Hirayama, N. Naruse, and T. Sakai, 'Shin Hifuku Zairyogakuı(Edited by K.Ishikawa), Doubun Shoin, p.111 (1989).

9. M. Hayashi, N. Kuroda, Y. Miura, and T. Sakai, Sen-i Gakkaishi, 34, T-193 (1978).

10. S. Kinoshita, T. namikata, Sen-i Gakkaishi, 14, 288 (1958).

11. H. Sanuki, K. kuri, and K. Ota, Sen-i Gakkaishi, 21,
91(1965).

12. H. Sanuki, K. Ito, and K. Ota, Sen-i Gakkaishi, 21, 506 (1965).

13. S. Matsukawa, Y. Sasabayashi, and M. Ishihara, Sen-i Gakkaishi, 42, T-256(1986).

14. S. Higuchi and A. Suzuki, Nippon Ifuku Gakkaishi, 40, 77 (1997).

15. Y. Minegishi and H. Arai, Yukagaku, 26, 85(1977).

16. T. Kawase, S.Sekoguchi, T. Fujii, and $M$. Minagawa, Text. Res. J., 56, 617 (1986). 